\title{
COMMENTS AND CRITICISM
}

\section{MORAL RESPONSIBILITY WITHOUT}

ALTERNATIVE POSSIBILITIES?*

\section{$\mathrm{T}$} he article I am commenting on, "Libertarianism and the Philosophical Significance of Frankfurt Scenarios," represents a significant turn in David Widerker's thinking about moral responsibility, or, more precisely, moral blameworthiness. ${ }^{1}$ He now holds that an agent can be morally blameworthy for an action of his even if it was not within his power to avoid performing it. This "avoidability-independent account of moral blame," as Widerker calls it, contrasts with his previous defense of avoidability as a requirement of moral responsibility. The article contains deep insights and a lot of good argument. My purpose in this comment, however, is mainly critical. After a brief presentation of Widerker's new position, I will state why I do not find it convincing.

In an important and influential article, ${ }^{2}$ Widerker put forward a powerful defense of the Principle of Alternative Possibilities (PAP) against criticisms based on so-called Frankfurt-style examples or Frankfurt scenarios. According to PAP, in Widerker's recent formulation, "[a]n agent $S$ is morally blameworthy for performing a given act $V$ only if he could have avoided performing it" (163). Frankfurt scenarios are cases in which an agent, fully on his own, does something which he would have been caused to do anyway by an alien factor had he shown some sign that he was not going to do it on his own.

\footnotetext{
* This paper falls under the research project "Belief, Responsibility, and Action" (HUM2006-04907), awarded and supported by the Spanish Ministry of Education and Science, to which thanks are due. Let me also thank Milagro Garrido, Tobies Grimaltos, Javi Hernandez, Marta Moreno, Eduardo Ortiz, Sergi Rosell, and Lino San Juan for useful comments on previous versions of this paper.

${ }^{1}$ Widerker, "Libertarianism and the Philosophical Significance of Frankfurt Scenarios," this JOURNAL, CIII, 4 (April 2006): 163-87.

${ }^{2}$ Widerker, "Libertarianism and Frankfurt's Attack on the Principle of Alternate Possibilities," Philosophical Review, cIV, 2 (1995): 247-61.

${ }^{3}$ Harry Frankfurt's formulation of PAP was as follows: "A person is morally responsible for what he has done only if he could have done otherwise" (Alternate Possibilities and Moral Responsibility," this JOURNAL, LXVI, 23 (December 4, 1969): 829-39, on p. 829). Widerker's formulation is more general, in that an alternative to performing a given action can be just to avoid performing it, and not necessarily to perform a different action. It is plausible to think that this was the spirit of Frankfurt's formulation as well.
} 
If cases of this sort are to imply the falsity of PAP, they have to satisfy at least two conditions. First, the circumstances that make the act unavoidable for the agent should not cause the agent to perform it. Widerker calls this condition IRR ${ }^{4}$ Here is Widerker's own formulation: "(IRR) There may be circumstances that in no way bring it about that a person performs a certain action; nevertheless, those very circumstances make it impossible for him to avoid performing that action" (164). A second condition is, of course, that the agent in such scenarios is morally responsible for his act. If at least one Frankfurt-style example meets these conditions, we have a case in which an agent is morally responsible for something he does even if he could not have avoided doing it, and PAP is then false. ${ }^{5} \mathrm{~A}$ rationale for condition IRR is that, if the act is unavoidable owing to circumstances that causally necessitate it, then the judgment that the agent is morally responsible for his act becomes unstable, and satisfaction of the second condition is jeopardized. Indeed, if that is the case, incompatibilists will (understandably enough) refuse to accept the agent's moral responsibility. But even compatibilists may hesitate for, depending on the nature of the circumstances that causally necessitate the action, it may appear as forced, coerced, or otherwise not freely performed.

Widerker contended that Frankfurt scenarios do not satisfy the IRR condition for choices or decisions, which are the natural loci of moral responsibility for libertarians. His argument for this contention took the form of a dilemma. ${ }^{6}$ For simplicity, suppose that the alien, inactive, though lurking factor in Frankfurt scenarios is an agent, Black. Think of the sign that Black employs for not intervening in the agent's (call him Jones) spontaneous process of deliberation and decision. Now, this is the dilemma. Either this sign is causally sufficient for Jones's decision, or it is not. If it is, then condition IRR is not satisfied, for the decision is made unavoidable by circumstances that causally determine it. If it is not, so that the sign is only a more or less reliable indicator of Jones's future decision, then there is no reason to think that the decision is unavoidable, and condition IRR is violated again. In either case, PAP is not refuted. On the first horn, there are no alternatives for Jones's deci-

\footnotetext{
${ }^{4}$ I have not been able to ascertain why he calls it this.

${ }^{5}$ In my recent book Moral Responsibility: The Ways of Scepticism (New York: Routledge, 2006), chapter 2, I have extensively defended PAP against Frankfurt-inspired and other criticisms of it. In the present paper I defend PAP further against Widerker's criticism.

${ }^{6}$ Cf. Widerker, "Libertarianism and Frankfurt's Attack on the Principle of Alternate Possibilities," pp. 251-56.
} 
sion, but he is not (for incompatibilists, at least) morally responsible for it. On the second horn, Jones may be morally responsible for his decision, but it certainly seems that he had alternatives to it: he could have decided otherwise, or at least could have avoided the decision he actually made. ${ }^{7}$

As Widerker writes: "The worry behind the dilemma objection is understandable. If in an IRR-situation the agent's decision is not causally determined, then why is it not within the agent's power to refrain from it?" (166). Since Widerker's forceful presentation, the dilemma defense has exerted strong pressure on the construction of prima facie plausible Frankfurt scenarios. Widerker holds that none of the attempts to design such scenarios in response to the dilemma defense has been successful. However, unlike what he used to think, he now contends that IRR-situations are nonetheless possible: "In the past, I have been skeptical about the prospects of providing a successful example of an IRR-situation. Since then, however, I have come to believe that such situations are conceptually possible" (166). Let us see the way in which Widerker has tried to show the possibility of these situations.

A chief difficulty in conceiving of IRR-situations is that it does not seem possible to reconcile the fact that the decision (or action) is not causally determined with its unavoidability. In an indeterministic setting, alternative pathways of some sort are bound to be present, and in some of these alternative pathways the decision is not made or the action is not performed. In fact, Widerker does not actually solve this difficulty. As we will see, his purported examples of IRRsituations are not such that in them the agent's decision is strictly unavoidable. However, Widerker resorts to a thesis that has emerged from the discussion about Frankfurt scenarios, namely, that it is not strictly necessary, for a situation to count as a counterexample to PAP, that in it the agent's decision is actually unavoidable. It is enough that the alternative pathways that may be present in it, which may include the agent's not making the decision he actually makes, are not within the agent's power or control; it is enough, in Widerker's terms, that they are not "actionally accessible" to the agent: "Call a state of affairs (event) E actionally accessible for an agent $S$, relative to a time $T$, if and only if $S$ has it within his power at $T$ to bring about $E^{\prime \prime}(167)$.

\footnotetext{
${ }^{7}$ A related defense of PAP was put forward by Robert Kane in his Free Will and Values (Albany: SUNY, 1985). However, it was Widerker's forceful presentation of it that brought this strategy to the center of the discussion about PAP and Frankfurt-style objections to it.
} 
Alternatives that are only causally possible, ${ }^{8}$ but not actionally accessible, to an agent do not suffice to defend PAP against counterexamples. To see why, imagine that, in a Frankfurt scenario, an agent deliberates competently and, on the basis of his own reasons, makes a morally wrong decision. Suppose that this decision is avoidable only as follows: before making it, the agent might, inadvertently and involuntarily, have stumbled on a stone and got hurt, with the result that he would have stopped deliberating and not have made the decision he actually made. If, in this example, the agent is morally responsible for his decision, it does not seem that such an alternative has anything to do with his responsibility: this alternative is not morally significant. Actional accessibility is a necessary condition for an alternative to be morally significant or, to use John Martin Fischer's well-known term, to be robust enough to explain the agent's moral responsibility. ${ }^{9}$ So, actionally inaccessible alternatives cannot be legitimately pointed to in order to vindicate PAP against putative counterexamples.

On the basis of the preceding remarks, we can understand Widerker's strategy. It consists in constructing examples where the agent's decision is not causally determined, but where the alternatives that are left, though causally possible, are not actionally accessible to the agent (and so not morally significant or robust). Strictly speaking, then, these are not properly IRR-situations, for the agent's decision is not unavoidable. They are, however, examples of a more general notion that includes the original IRR-situations as particular cases of it. Widerker calls this more general notion or condition G-IRR: "There may be circumstances that in no way bring it about that a person performs a certain action; nevertheless those very circumstances leave him with no morally significant alternative to performing that action" (175). Notice that having no alternative to what one does is a particular way of having no morally significant alternative to it. Corresponding to this more general definition of an IRR-situation, Widerker suggests the following more general formulation of PAP: "An agent $S$ is morally blameworthy for $V$-ing at $T$ only if $S$ had a morally significant alternative to V-ing at $T$ " (175, note 24). It is plausible to think that this formulation is faithful to the

\footnotetext{
${ }^{8}$ Widerker defines a causally possible state of affairs $E$, relative to a time $T$, as follows: " $E$ obtains in some possible world $W$ that up until (and including) $T$ has the same history and the same laws of nature as the actual world" (167).

${ }^{9}$ It was Fischer, in fact, who first pressed this point, according to which alternative possibilities in Frankfurt scenarios have to be robust, in the sense of being explanatorily relevant for the agent's moral responsibility, if resort to them is to be successful as a defense of PAP. Cf. Fischer, The Metaphysics of Free Will (Cambridge: Blackwell, 1994), pp. 140-47.
} 
original inspiration of PAP: alternative possibilities mentioned in this principle are plausibly taken to be morally significant or robust. Strictly speaking, then, the scenarios Widerker depicts are examples of G-IRR-situations, rather than of IRR-situations, and they are purported counterexamples to the general formulation of PAP, rather than to the original formulation of it. Having this in mind, however, we shall use "IRR-situations" to refer to G-IRR-situations (which, of course, include IRR-situations proper), and with "PAP" we will refer to the general formulation of this principle we have just indicated. Let us now have a look at Widerker's purported examples of IRR-situations.

Widerker depicts his IRR-situations on the basis of an initial example of a Frankfurt scenario, which he dubs "Promise Breaking." The example features Jones, who has promised his uncle to visit him in the hospital before an important operation that the old man will undergo early next morning. On his way to the hospital, Jones meets Mary, a former girlfriend of his, whom he has not seen for a long time. Mary tells Jones that she will be in town for just a couple of hours and that she would most like to spend those hours with him. Jones feels strongly attracted by Mary's proposal. He knows, however, that, if he accepts it, he will not be able to keep the promise he made to his uncle, for the visit time will be over. So he deliberates whether to keep his promise. Unbeknownst to him, however, another person, Black, wants Jones to break that promise and has the means to ensure this result. However, Black will remain fully inactive unless Jones shows a sign that he will finally decide to keep his promise. In fact, Black has no need to intervene, for Jones shows no such sign and decides on his own to break his promise and to spend time with Mary (cf. 164).

Widerker contends that this example falls prey to the dilemma defense and is not an IRR-situation. However, elaborating on this example, Widerker constructs two putative examples of IRR-situations. The first he calls "Z-Persons." Suppose that there actually are persons (Z-Persons) who, in morally laden choice situations in which they feel a strong temptation to act immorally, invariably behave as follows: either they succumb to the temptation and make the wrong decision or they lose consciousness, regaining it shortly afterwards. Widerker writes:

Now suppose that Jones is such a person, and he is in the kind of situation described in Promise Breaking, except that this time there is no Black waiting in the wings. Suppose also that Jones does not know that he is subject to the said behavioral pattern. As things transpire, Jones decides at time $T$ to break the promise on his own (169). 
Widerker contends that this is an IRR-situation. Jones's decision to break his promise is not causally determined. It might not take place. However, the only alternative to it in which Jones does not make that decision, namely Jones's loss of consciousness (assuming that this is not under Jones's control), is not actionally accessible to him, and so is not morally significant (or robust). Jones, then, does not have it within his power to decide to keep his promise, which would be a morally significant alternative. Notice also that the example does not succumb to the dilemma defense, for it does not feature a counterfactual intervener or a sign of Jones's future decision concerning which the dilemma could arise.

Widerker's second example is called "Brain-Malfunction-W." It again features Jones's deciding at time $T$ to break his promise. A different decision (which would be a morally significant alternative) is not open to him, for

... shortly before beginning to deliberate, he undergoes a neurological change as a result of which one of the (neurological) causally necessary conditions for his deciding otherwise, a condition which we may call $N$, does not obtain. Let us also assume that all this is unknown to Jones (who believes that he can decide to keep his promise), and that N's absence does not affect his deliberation process (170).

Since $N$ is causally necessary for Jones's decision to keep his promise, $N$ 's absence is causally sufficient for Jones's not deciding to keep his promise. This absence, however, is not causally sufficient for his (actual) decision not to keep his promise. This decision might not take place, but the alternatives to it (for instance, becoming distracted and temporarily forgetting about his deliberation), though causally possible, are not actionally accessible to Jones, and so not morally significant.

It seems, then, that we have two examples of an IRR-situation. More exactly, they are examples of a G-IRR-situation, for, though Jones's decision is not, strictly speaking, unavoidable, the alternatives to it are not morally significant. However, as Widerker himself accepts, in addition to its being an IRR-situation, an example has to satisfy a second condition if it is to be a counterexample to PAP, namely that the agent is morally responsible for what he did. In the purported examples of IRR-situations featuring Jones, he is to be morally blameworthy for his decision to break his promise, for otherwise PAP will remain safe. Now, provisionally leaving aside the question whether Widerker's examples are in fact IRR-situations, my criticism of Widerker's position will rest crucially on the contention that his examples do not satisfy the indicated condition of moral blameworthiness. More cautiously, my contention would be that there are fairly 
strong reasons against the judgment that, in the proposed examples, the agent is morally blameworthy for the decision he makes.

It is quite clear that Widerker believes that, in both of his examples, Jones is morally blameworthy for breaking his promise. Widerker's new, avoidability-independent account of moral blame (AI-BL) takes the following form:

(AI-BL) An agent $S$ is morally blameworthy for deciding-to- $V$ at time $T$ if and only if

(i) $S$ decides-to- $V$ at $T$ on his own.

(ii) $S$ decides-to- $V$ at $T$ being aware that doing so is morally wrong.

(iii) $S$ believes that he could have decided otherwise, or believes that he has no good reason to think that he could not have decided otherwise.

(iv) $S$ does not think that, in the circumstances, deciding-notto- $V$ at $T$ is irrational (180).

It seems that Jones, both in Z-Persons and in Brain-Malfunction-W, satisfies these four conditions; so, if the account is correct, he is morally blameworthy for breaking his promise. The account does not require that the agent be actually able to decide otherwise, but only that he believe he can do so, and this is something that Jones believes in both cases, though his belief is false.

As I said earlier, I think there are serious reasons for doubting that Jones is actually morally blameworthy in either case. Let me place my criticism in the context of contemporary dialectics concerning moral responsibility. My objections to Widerker are related to what Fischer has called "weak reasons-responsiveness," which he takes to be a requirement for moral responsibility. ${ }^{10}$ Roughly speaking, in deliberating and deciding, an agent satisfies weak reasons-responsiveness just in case, keeping constant the mechanism of deliberation and decisionmaking that he employs in the situation at hand, there are some possible scenarios or possible worlds in which there is a sufficient reason to decide and do otherwise, he recognizes that reason and decides and does otherwise. It is very plausible that something like this condition is necessary for moral responsibility. Think of someone (the example is Fischer's) who decides to steal a book and does so. Fischer writes: "If (given the operation of the actual kind of mechanism) he would persist in stealing the book even if he knew that by so acting

\footnotetext{
${ }^{10} \mathrm{Cf}$. Fischer, The Metaphysics of Free Will, pp. 166-67. Fischer has slightly modified the requirement in his book Moral Responsibility and Control (New York: Cambridge, 1998), coauthored by Mark Ravizza. In this book, Fischer and Ravizza call the modified requirement "moderate reasons-responsiveness." I will ignore the distinction, for it is not essential to my argument.
} 
he would cause himself and his family to be killed, then the actual mechanism would seem to be inconsistent with holding him morally responsible for his action." "This thief's mechanism of deliberation and decision-making is not responsive to reasons; it is a faulty mechanism, which compromises the agent's capacity for rational deliberation and decision-making and undermines the judgment that he is morally blameworthy for his decision and action. Whether a certain process satisfies Fischer's weak reasons-responsiveness depends on the truth of certain counterfactuals about what the agent would decide and do if certain conditions were to hold, but it does not require that the agent has access to the possible worlds where these conditions hold. It does not assume, then, that moral responsibility for a decision or action requires that an agent is actually able to decide and do otherwise.

Now, a related condition should hold for the specific case of moral reasons. Some degree of responsiveness to moral reasons is plausibly taken to be a requirement for moral responsibility. If, keeping constant the mechanism of deliberation and decision-making that an agent employs in a particular situation, and supposing that he faces a temptation to act immorally, he would never decide in a morally right way, no matter how strong and decisive his moral reasons may appear to him, it seems that something is wrong with the agent's deliberative faculties in this situation. And this stands in the way of judging him morally blameworthy for his decision. Now, this seems to be precisely the case with Jones in Widerker's examples. Let me argue for this point.

As Fischer's weak reasons-responsiveness suggests, an important assumption of the judgment that an agent is morally responsible for what he decides is, for compatibilists and incompatibilists alike, that the decision arises out of a normal process of practical deliberation and decision, which in turn presupposes in the agent a sound capacity for practical and moral reasoning. This capacity can be impaired in several ways. One of these ways may be the belief that one does not have alternative decisions or actions within one's power. This belief may temporarily damage the indicated capacity, vitiate the process of deliberation, and affect one's moral responsibility. In Widerker's account, the third condition rules out this possibility, and we are entitled to assume that, in both examples, Jones believes (falsely, as it happens) that he can decide to keep his promise. But there are other ways in which the impairment may occur. Being insensitive to moral reasons (being "morally blind") is one of them. Widerker's second condition seems to rule out this possibility as well. In his examples,

${ }^{11}$ Fischer, The Metaphysics of Free Will, p. 167. 
we should assume, it seems, that Jones is sensitive to moral reasons for keeping his promise. But, beyond being sensitive to moral reasons, an agent with a normal, unimpaired capacity for moral and practical reasoning and decision-making should also be able to decide (and possibly act) according to these reasons. And this is an ability that Jones lacks in both of Widerker's examples. As Widerker depicts the cases, the actual apparatus of practical reasoning and decisionmaking that Jones employs is such that he is not able to decide as moral reasons counsel. Deciding to keep his promise is not causally possible for Jones, and so is not within his power. And if this is the case, Jones's capacity for moral deliberation and decision-making is seriously impaired, so that the judgment that he is morally blameworthy for the decision he makes in the circumstances becomes highly dubious, to say the least. Let me clarify and develop this point.

First of all, I would like to emphasize that my objection to the judgment that Jones is morally blameworthy for his decision to break his promise does not rest on the fact that he lacks morally significant alternative possibilities, for this would clearly beg the very question at issue. My objection has rather to do with the fact that the apparatus of deliberation and decision-making that Jones is using in the actual sequence is abnormal or impaired. In the context of my objection, the fact that Jones cannot decide to keep his promise, no matter how strong or decisive the moral reasons for this decision may appear to him, is only a symptom or a consequence of the faulty nature of his actual apparatus of practical and moral reasoning. And it is this faulty nature, and so a feature of the actual sequence, rather than the lack of robust alternatives, that backs my doubt about Jones's blameworthiness.

The sense in which Jones's actual apparatus of practical and moral reasoning is faulty can be seen as follows. Consider first Z-Persons. Imagine that, on his way to the hospital, Jones meets a friend of his who is a doctor. Jones tells his friend about the operation that his uncle is about to undergo and he comes to know from his friend how dangerous and risky the operation is, and how likely it is that his uncle will not survive it. We may also suppose, if we want, that the old man has generously helped Jones in many ways during his life, and that Jones feels deeply grateful to him for that. Jones now sees in an especially clear way what strong and decisive moral reasons he has for visiting his uncle. Afterwards, he meets Mary as in the original story and, though he still feels strongly tempted by the prospect of spending time with her, he now sees clearly that his reasons for visiting his uncle are more important and decisive than his reasons for staying with Mary. However, as he is a Z-person, he is, in fact, 
causally unable to do what a normal moral agent would rightly be expected to do in the circumstances, namely, deciding to keep his promise and visiting his uncle. Now, I would think that an agent who, in a deliberative situation like this, is causally unable to make the right moral decision, does not have a sound and unimpaired capacity for practical reasoning and should not be judged to be (at any rate fully) morally blameworthy for the decision he makes, no matter whether one is a compatibilist or an incompatibilist.

Moreover, it would be pertinent to ask for more information about the example, for, depending on how it is interpreted, there might be additional reasons for criticism. In particular, it would be important to know under what circumstances the nonrobust alternative of Jones's fainting is supposed to take place. Suppose that it may occur at any time while Jones is deliberating and merely considering the reasons for either decision. In this case, it seems that he does not have enough control over his decision at $T$ to break his promise. Though he actually made that decision, he might equally have fainted instead, so that the judgment that he is morally blameworthy for it is eroded. On this interpretation, Widerker's example is not immune to traditional luck objections to incompatibilism. Suppose instead that Jones would faint only as a result of his attending seriously to his moral reasons and his making an effort to decide according to them. In this case, Jones may be morally blameworthy for his decision to break his promise, but now he has morally significant, robust alternatives. Jones would therefore be blameworthy for his decision partly because he should and could have made an effort to decide otherwise but did not. On this interpretation, the example would not be a G-IRR-situation.

Similar remarks can be made with respect to Brain-Malfunction-W. In this example, after neurological condition $N$ has ceased to obtain, Jones will not be able to decide according to his moral reasons, no matter how strongly and decisively these reasons may appear to him. But this causal impossibility of alignment between reasons and decision is a clear sign that something is going wrong with Jones's deliberative and decision-making apparatus in that situation. It seems, then, that Jones does not reach his decision to break his promise with a sound and unimpaired capacity for practical and moral reasoning, and this undermines the justification for judging him morally blameworthy for his decision. On the other hand, depending on what the absence of condition $N$ allowed Jones to do, the example might not be a G-IRR situation. By hypothesis, this absence allows Jones to appreciate the force of moral reasons. Suppose that it also allowed him to adopt a favorable attitude toward complying with them, as a preliminary step in the process of deciding to keep his promise. Even if 
the process could not finally be completed, adopting such an attitude would seem to be a morally significant alternative, and the example would not be a G-IRR-situation. Suppose, however, that the absence of $N$ did not even allow him to adopt a favorable attitude toward a decision that would honor moral reasons, or to take any other preliminary step addressed to that decision. If so, this would reinforce our initial suspicion that, in the situation described in the example, we were not facing an agent with unimpaired faculties for practical deliberation. An agent unable to take any steps towards deciding according to moral reasons, no matter how strong or convincing he may find them, does not seem to be a normal deliberator, and the case for not holding him (fully) morally responsible is enhanced. ${ }^{12}$

Though the possibility that Widerker, or someone else, can come up with other cases of IRR-situations in which the agent is morally responsible for his decision cannot be ruled out a priori, there are some general considerations, prompted by the preceding criticisms, that suggest that such a possibility is not in the offing and even that cases like it may not be possible. To conclude, let me argue for this point.

An important advantage of Frankfurt scenarios is that they tend to raise a natural and very strong intuition that, in them, the agent is morally responsible for his decision, for this decision is, at least apparently, ensured only by the presence of a purely counterfactual factor, which remains fully inactive throughout the whole process. The agent seems to deliberate and decide spontaneously, with no apparent hindrance or constraint. Moreover, there is nothing that prevents us from assuming that the agent's actual apparatus of practical reasoning is perfectly sound and reasons-responsive. Suppose, nonetheless, that Frankfurt scenarios fall prey to the dilemma objection or are otherwise irredeemably flawed. ${ }^{13}$ In Widerker's alternative proposal, however, the intended result, namely either a morally wrong decision or morally irrelevant alternatives, is not ensured by a counterfactual factor (which would open the door to the dilemma

\footnotetext{
${ }^{12}$ Though I will not develop this point here, I am confident that similar criticisms of Widerker's proposal can also be raised on the basis of other views of control and moral responsibility, such as Frankfurt's, Gary Watson's, or Susan Wolf's. It seems clear that, in Widerker's examples, and under quite plausible assumptions, Jones will not be able to decide and act in accord with either his second-order volitions or his values.

${ }^{13}$ Given the number, variety, and ingenuity of Frankfurt-friendly examples now on offer, I am aware that this is a bold assumption indeed, but let us accept it for the sake of argument. Some support for it can be found in my Moral Responsibility (chapter 2). There I try to show that, even if some of the recently proposed examples can actually escape the dilemma objection, they may face other, no less significant, difficulties.
} 
objection), but by some causal feature of the actual sequence and, in particular, of the agent's actual neurological and psychological constitution. Now an agent who is internally (neurologically or psychologically) unable to make the right moral decision, no matter how strong and convincing the moral reasons he may have for that decision, does not seem to have a sound capacity for moral reasoning and decision-making. And the problem is that, in these conditions, and unlike what tends to happen in Frankfurt scenarios, the intuition that the agent is morally blameworthy for his decision becomes blurred or is simply absent. Whether this problem can be solved is an open question, but, at first sight, solving it does not look like an easy task. In this comment, I have tried to show that, at any rate, Widerker's purported examples of IRR-situations do not solve it.

University of Valencia

CARLOS J. MOYA 